\title{
Analysis of the directions of the development of mechanization units for processing the near- trunk area in the garden
}

\author{
Vladimir I. Konovalov ${ }^{1, *}$ and Sergey I. Konovalov ${ }^{2}$ \\ ${ }^{1}$ Chair of «Processes and machines in agribusiness» of the faculty of mechanization of Kuban State \\ Agrarian University named after I. T. Trubilin, 350044, Krasnodar, Russia. \\ ${ }^{2}$ Training-experimental farm "Krasnodarskoe" of Kuban State Agrarian University named after I. T. \\ Trubilin, 350044, Krasnodar, Russia.
}

\begin{abstract}
The final cost of gardening products is influenced by many factors including the tillage costs. Most often, the soil in the near-trunk area of gardens is kept under black fallow, and soil treatment is usually carried out by rotary machines with a vertical axis of rotation. The article presents the analysis of directions of the development of mechanization units for soil tillage in conventional in the near-trunk area of gardens due to information of open registers of FIIP (Federal Institute of Industrial Property) of Russia. As a result of the analysis, the classification of the main types of technical results is performed and the main requirements for tillage machines are formulated, the implementation of which will increase the efficiency of gardening.
\end{abstract}

\section{Relevance of research}

Currently, gardening is one of the most profitable areas of agriculture, but at the same time, the cost of final products is also one of the highest in the industry. This is primarily due to the significant time from the laying of new perennial plantings to the moment of sale of products, as well as the low level of mechanization. The low level of mechanization is regulated not only by the specific working conditions in the near-trunk area of gardens, but also by the manual harvesting, which is aimed at improving the quality and sales parameters of the crop.

The main purpose of the soil cultivation technology in perennial plantations is to preserve and improve the fertility of soil horizons, giving it a structural state that would most fully correspond to the favorable conditions of growth and fruiting of perennial crops, including the preservation and accumulation of moisture, its temperature and other modes [1, 2, 3].

The system of soil horizon maintenance in the garden is divided into black fallow, sodding, parosideral, soddy-humus and soddy-mulching $[4,5]$.

After analyzing these systems, we can conclude that different processing and maintenance technologies are used for the soil in the aisles and trunk strips. However, all

\footnotetext{
*Corresponding author: konovalov.v.i@mail.ru
} 
these systems provide for the maintenance of near-trunk and inter-trunk areas of perennial plantings under black fallow. Only the soddy-humus system provides for the creation of a mulch layer in the near-trunk area after the fifth or sixth season. At the same time, this approach to the maintenance of the near-trunk area is possible only in climatic zones with intensive precipitation or in gardens with irrigation.

\section{Problem statement}

Garden tillage machines for processing of near-trunk areas can be divided into machines with passive and rotary working bodies [6-8]. Machines with rotating working bodies most fully meet the agrotechnical parameters.

Rotary machines with a vertical axis of rotation are more productive and significantly less energy-intensive in comparison with machines with a horizontal and inclined axis of rotation, and they use power more efficiently. In addition, when working with such machines, mixing of the soil in horizontal planes is minimized and it favorably will affect the accumulation and preservation of moisture in it.

Currently, the world machine industry produces a number of tillage tools that are only modifications or partially modernized samples in comparison with the prototypes developed in the 50-60s of the last century. For full mechanization of domestic gardening, it is necessary to establish the production of agricultural tools that meet all world requirements and directions for improving the means of mechanization of gardening.

The process of creating new machines and units is very time-consuming and includes a list of separate, but interrelated stages, which can include the process of analyzing the current state and directions of the development of mechanization units, the formation of initial requirements for a specific technological operation, the design and creation of a prototype, its testing and revision of the test results. Of all these stages of the analysis of the current state and directions of the development is one of the most thorough and responsible, because the re-development of technical units or their individual elements is irrational, and sometimes harmful.

\section{Presentation of the main research material}

In the process of analyzing the directions of the development of mechanization units for processing the near-trunk area in the garden, we systematized data from open registers of the Federal Institute of Industrial Property of the Russian Federation. The results obtained allowed us to form a conclusion that the directions of the development of gardening mechanization units can be divided into the following types according to the technical result:

1. improving the quality of the technological process;

2. increasing the reliability of the technological process;

3. reducing the energy intensity of the process.

In addition, the analysis made it possible to identify common technical features and ways to achieve the set technical result.

Technical devices aimed at improving the quality of the technological process of processing the near-trunk area have the following common features [9-11].

The agricultural machine designed for processing the near-trunk areas of the garden (Fig. 1) includes a supporting frame 1 , which is attached to the mounted device 1 via a parallelogram mechanism 3 with a hydraulic cylinder 4. The Milling drums 6 receive rotation through drive shafts installed in the housing of a cylindrical gearbox 5 , which can rotate relative to the central input shaft 7 at an angle of up to $180^{\circ}$. The housing 5 itself is mounted on the supporting frame 1 using vertical drive shafts. The machine is equipped 
with a dipstick 8 to control the rotation mode of the housing of the cylindrical gearbox 5 when copying tree boles in the near-trunk area. The outer edge of the frame is equipped with a copier 15 with a correction mechanism.

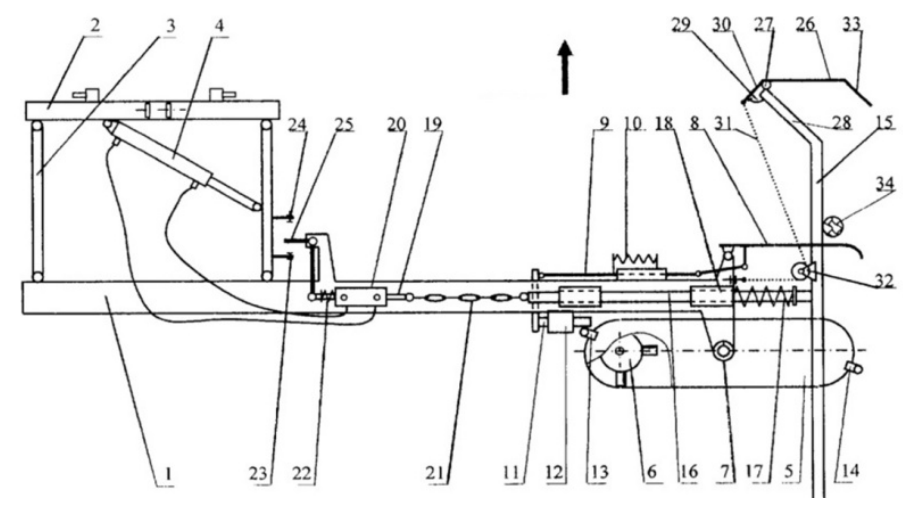

1 - supporting frame; 2 - mounted device; 3 - parallelogram mechanism; 4 - hydraulic cylinder; 5 cylindrical gearbox; 6 - milling drum; 7 - central input shaft; 8 - dipstick; 9 - plunger; 10 - spring; 11 - finger; 12, 18 - sleeve; 13, 14, 23, 24, 29 - thrust; 15 - cam; 16 - rack; 17 - rack spring; 19 slide valve; 20 - hydraulic control valve; 21 - swivel draft; 22 - spring of compression; 25, 26 lever; 27 - vertical hinge; 28, 33 - bent part of cam; 30 - short arm; 31 - flexible draft; 32 - roller;

Fig. 1. Construction scheme of the machine for processing the near-trunk areas in the garden

In the working mode of the agricultural machine, when cultivating the soil in the garden, the right edge of the milling drums 6 moves along the near-trunk area. The copier 15 with its bent part 33 installed using the lever 26 slides along the trunks of perennial plantings. The housing of the cylindrical gearbox 5 with milling drums 6 , due to the stop 13 of the control mechanism installed on it, is fixed by the finger 11 in the set position. When deflecting the dipstick 8, due to interaction with the trunk of the tree from its original position, due to the levers, it removes the finger 11 from the thrust 13 . Due to the forces of the reaction of the soil to the knives of the milling drums 6 , the housing of the cylindrical gearbox 6 begins to rotate axially relative to the central input shaft 7 . After passing the tree trunk, the force acting on the dipstick 8 ceases, and due to the spring 10, the finger 11 again resumes its contact with the thrust 14 , located on the opposite side of the housing of the cylindrical gearbox 5, which allows it to avoid turning at an angle greater than $180^{\circ}$.

During operation of the agricultural machine, the copier 15 is in constant interaction with the rods and fixes the housing of the cylindrical reducer 5 with the milling drums 6 at a pre-set equal distance from the axis of the tree rows. In the case of interaction of the copier 15 with the tree trunk, which is separated from the axis of the line of the row, due to the created pressure force, it is deflected to the left from the axis of the row by a flexible draft 31 . The pressure force of the spring 17 on the rack 16 is overcome and reduces the tension force of the hinge rod 21, which interacts with the spool 19 of the hydraulic distributor 20. Due to the compression spring 22, the slide valve 19 is displaced, thereby redirecting the flow of hydraulic fluid to the hydraulic cylinder 4, which, due to the parallelogram mechanism 3, displaces the entire supporting frame 1 from the axis of the row. At the end of the interaction of the copier 15 with the tree due to the spring, the supporting frame returns to its original position.

From the present design schemes of agricultural machines, it can be concluded that all technical devices for improving the quality of the technological process of soil treatment in the near-trunk area are used copying devices with different versions. 
In technical devices aimed at improving the reliability of the technological process, the garden milling cutter with a variable width of the FPS-200 and the design scheme specified above [12-17] are used as prototypes.

When using the FPS-200 milling cutter as a prototype, technical devices have a number of common features. The agricultural machine (Fig. 2), containing frame 3 with the housing 2 with the milling drum 1 is proposed for tillage in the near-trunk area of perennial plantings. The agricultural machine is attached to the power unit by means of hinges 4 secured to the frame 1 via the parallelogram mechanism 5 and has an active PTO shaft of the tractor. From the right edge of the casing 2 of the milling drum 1, which is located on the side of the processed near-trunk area, a bump 17 with a branch lifter 18 is installed.

The operation of the proposed agricultural machine is carried out in the following sequence. Before starting work with the hydraulic cylinder 6, the rack spring 17 of the casing 2 of the milling drum 1 is placed flush with the perennial plantings. After that, the drive of the agricultural machine is switched on, the lifting mechanism of the tractor hitch is moved to the working position and the working stroke starts. In the process of its movement along the near-trunk area, the hydraulic cylinder 6 due to the spring 15 presses the frame 3 to the rods. The stem lifter 18 lifts the low-lying branches and stems to prevent damage, and the milling drums process the soil directly near the stem. When the rack spring 17 interacts with the stem of a protruding perennial plant, there is a force that is transmitted through the frame 3 to the spring 15. The resulting force overcomes to the pressure of the spring and, due to the hinged parallelogram mechanism 5, shifts the frame 3 away from the row.

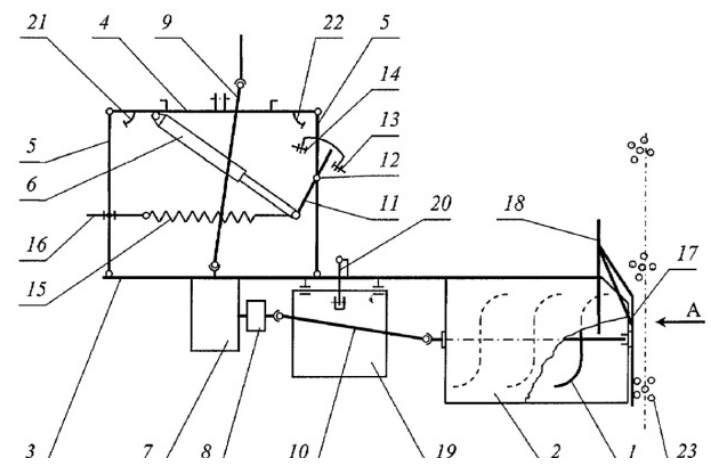

1 - milling drum; 2 - casing; 3 - frame; 4 - hinge; 5 - parallelogram mechanism; 6 - hydraulic cylinder; 7 - reducer; 8 - safety clutch; 9,10 - crankshaft; 11 - lever; 12 - axis; 13, 14, 21, 22 traction; 15 - spring; 16 - rod; 17 - bump stop; 18 - branch lifter; 19 - support; 20 - mechanism of processing depth adjustment, 23 - tree

Fig. 2. Agricultural unit for soil processing in near-trunk areas

Since the working bodies of the milling drum 1 have a bent L-shaped shape, when interacting with the soil, a reaction occurs that tends to take them away from perennial plantings. Thus, by adjusting the spring force 15, it is possible to achieve a state of the milling drum that is close to equilibrium, which will allow the milling drum 1 to be kept flush with perennial plantings. After the removal of the bump from the trunk, the resulting force ceases its action, and due to the hydraulic cylinder 6 , the milling drum 1 returns to the near-trunk area. Adjustment of the tillage depth is achieved by changing the length of the rod 16 of the depth adjustment mechanism 20 . The greatest removal of the milling drum 1 is limited by the size of the stroke of the hydraulic cylinder rod 6 and the stop.

The proposed design schemes as prototypes, which use the design scheme specified earlier (Fig. 1) have such differences that the mechanism for controlling the rotation of the 
body is equipped with a locking device of various designs and an additional damper, or an electrical system, as well as the hinge joint of the frame bar is equipped with a locking mechanism with a safety device (Fig. 3).
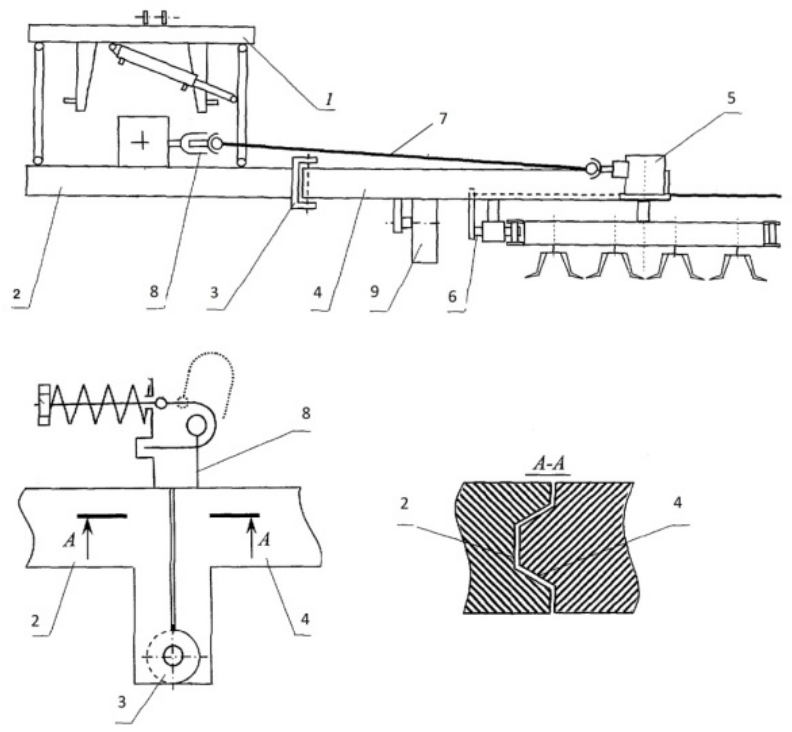

1 - attachment device; 2 - main bar; 3 - hinge; 4 - additional bar; 5 - gearbox with milling drums; 6 - rotation control mechanism; 7 - drive of milling drums; 8 - locking mechanism with a safety device; 9 - support and adjustment wheel

Fig. 3. A machine for processing tree trunks in the garden with a turn control mechanism and a safety mechanism

Such design and technological schemes allow to increase the reliability of the technological process of processing of near-trunk areas in the garden, increase the technical reliability of the machine and reduce damage to perennial plantings when working bodies meet with various obstacles. However, the production of serial designs will be more metalintensive, paired products will work under alternating dynamic loads, which will lead to rapid wear, and equipping the machine with an additional electrical system will lead to more difficult operation and the need for qualified personnel.

Recently, much attention has been paid to reducing the energy consumption of the technological process of the near-trunk area processing in the garden. This problem can be solved by applying vibration to reduce the specific drag or by using non-traditional working bodies that are rotated by the pressure difference on its working surfaces [18-22].

The same design and technological scheme is used in the designs of garden cultivators using vibration (Fig. 4).

The rotary garden cultivator consists of a frame 1 with a vertical shaft 3 mounted on it through a reducer 2 , on which the rotor is fixed and working bodies in the form of L-shaped knives and a source of energy and vibration of various designs.

In the rotary garden cultivator shown in figure 4, a disk 6 with a vibration source 7 is placed on the vertical shaft. The vibration source 7 is made in the form of an inductor connected to a pulse current source 8 . A freely moving steel ball 9 is installed inside the inductor, and the source 8 includes an autotransformer 10 and a thyristor 11. 


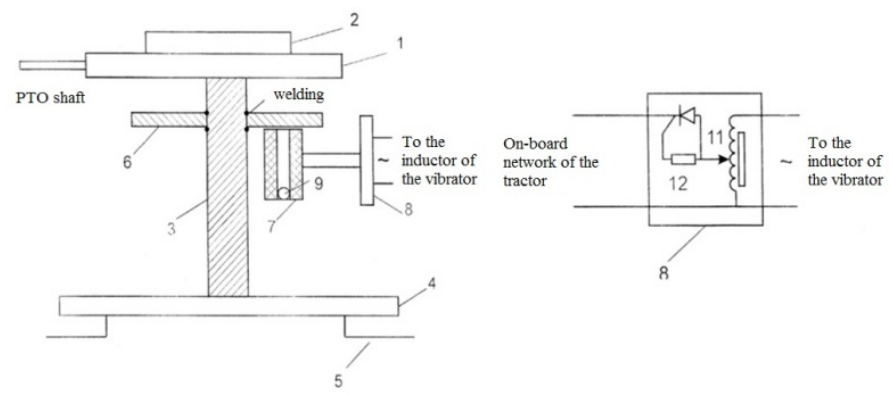

1 - frame; 2 - reducer; 3 - vertical shaft; 4 - rotor; 5 - knife; 6 - metal disk; 7 - vibrator; 8 - pulse current source; 9 - steel ball; 10 - autotransformer; 11 - thyristor; 12 - resistance

Fig. 4. Rotary garden cultivator for tillage of the near-trunk areas

When working with a rotary garden cultivator, working bodies in the form of L-shaped knives receive rotation from the PTO of the tractor through the gearbox 2 and the vertical shaft 3. From the tractor's electrical network, the voltage supply to the source 8 will be switched on, which will create pulses on the inductor coil. At the same time, an electromagnetic field occurs in the steel ball 9, due to which it produces high-frequency blows against the metal disk 6 at a high speed. Due to these blows, vibration occurs, which is transmitted directly to the working bodies themselves.

When using machines of these structures, there is not a significant decrease in the resistivity, which is not due to a large amount of frequency and amplitude of vibrations.

The use of a vane impeller as working bodies is realized in a unit for cultivating soil without turning the layer (Fig. 5), consisting of a frame 1 with a 3-point hitch 2, with a mechanism fixed to it for changing the depth of processing and working bodies 5 . Working bodies 5 are made in the form of vane impellers 8 with a curved surface and a triangular cross-section cutter. The working bodies 5 are fixed and rotated by the shaft 7 [23].
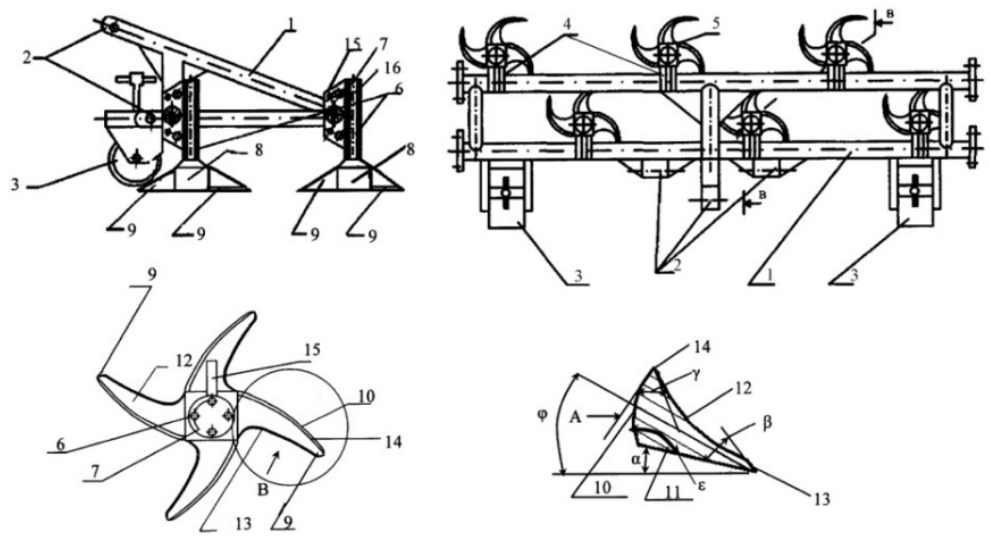

1 - frame; 2 - three-point hitch; 3 - mechanism of changing the depth of processing; 4 - bracket; 5 working body; 6 - stand; 7 - shaft; 8 - blade impeller; 9 - blade; 10 - back face; 11 - lower face; 12 - lifting face; 13 - main cutting edge; 14 - auxiliary cutting edge; 15 - bracket; 16 - bearing

Fig. 5. A unit for cultivating the soil of the near-trunk zone in inter-rows of fruiting gardens

When the unit is working, the working parts of the unit are lowered to the working position, and its movement starts. During the operation of the unit, the peripheral part of the blade 8 starts to immerse into the soil, the back face 10 of which is affected by increased 
pressure from the soil. Due to the manufacture of a curved blade impeller, the pressure created on the back faces 10 and edges 13 and 14 will be different, which will create a torque and begin to rotate the working body 5 on the shaft 7 .

The cutting edge cuts, deforms and shifts the soil layer along the lifting face, which crumbles against the edge, due to the gravity of the soil layer. The lower face is made at angles that reduce the friction forces on the ground, the force of ejection and the cutting force, which results in further deepening of the impeller. When the working body meets an obstacle, the force of soil pressure on the edge increases sharply and exceeds the pressure of the soil on the face, the blade stops and begins to circumvent the obstacle due to its curvature. After completing the bypass, the blade impeller begins to rotate and continues the cutting process.

Effective operation of this technical device will be difficult due to the heterogeneous physical and mechanical composition of the soil, since it is applicable in gardens with a difference in soil density of no more than $5 \%$.

\section{Conclusions}

After analyzing the various systems of soil maintenance in the garden, agrotechnical requirements and directions of the development of gardening mechanization units, it can be concluded that the most effective soil treatment in the near-trunk areas of the garden will be produced by machines that meet the following requirements:

- tillage of the near-trunk area should be carried out without omissions and blemishes;

- $\quad$ exposure to a tree should not cause damage to it;

- design of the machine should be less metal-intensive and include hydraulic or other systems;

- $\quad$ operation of the machine should not require highly qualified personnel;

- $\quad$ use of the machine must be possible on any soils;

- $\quad$ tillage process should be less energy intensive.

\section{References}

1. Soht K. A. Soil structure. Technologies and technics. Problems and solutions [Text]: manual / K. A. Soht, E. I. Trubilin, V. I. Konovalov. (Krasnodar: KubSAU, 2018).

2. Tarasenko B.I. Soil processing [Text]: manual / B. I. Tarasenko, A. S.Naydenov, N. I. Bardak, V. V. Tereshchenko. (Krasnodar: KubSAU, 2015).

3. Tarasenko B. I. Increasing soil fertility in Kuban [Text]: monograph / B. I. Tarasenko. (Krasnodar: KubSAU, 2014).

4. Buzoverov, A.V. Reproduction of soil fertility in gardens /A.V. Buzoverov, V. P. Popova, V. A. Plakhotin / Agrarian science. v 5. pp. 12-14 (2004).

5. Fruit growing [Text]: manual / Yu. V. Trunov et al. (M.; KolosS, 2012). ISBN 978-59532-0833-8

6. Klenin N.I. Agricultural machines [Text]: manual / N. I. Klenin, S. N. Kiselev, A. G. Levshin (M.: KolosS, 2008).

7. Sokht K.A. Disk harrows and huskers. Design of technological parameters [Text]: textbook. manual / K. A. Sokht, E. I. Trubilin, V. I. Konovalov., (Krasnodar: KubSAU, 2014).

8. Rational system of multifunctional aggregates for mechanization of plant growing / G.G. Maslov, E.M. Yudina, A.S. Serguntsov, R.O. Evglevsky // Research Journal of 
Pharmaceutical, Biological and Chemical Sciences. Vol. 9, № 5, pp 1177-1185, (2018).

9. Patent 2326516 RF, MPK A01V 39/16. Machine for processing of the near-trunk areas in the garden / Brosalin V. G., Manayenkov K. A. № 2006113259/12; Declared 19.04.2006; Publ. 20.06.2008; Bul. № 17

10. Patent 2335109 RF, MPK A01V 35/16. Machine for processing of the near-trunk areas in perennial gardens / Brosalin V. G., Manayenkov K. A. \#. №2006113358/12; Declared 19.04.2006; Published 20.11.2007; Bul. №28

11. Patent 2004118770 RF, MPK A01V 39/16. Machine for processing of the near-trunk areas in gardens / Brosalin V. G., Manaenkov K. A. - №2 004118770/12; Declared 21.06.2004; Published 10.01.2006; Bul. № 01

12. Patent 2006113259 RF, MPK A01V 39/00. Machine for processing of the near-trunk areas in gardens / Brosalin V. G., Manaenkov K. A. - №2006113259/12; Declared 19.04.2006; Published 27.12.2006; Bul. №36

13. Patent 2272388 RF, MPK A01V 39/16. Machine for processing of the near-trunk areas in the garden / Brosalin V. G., Manaenkov K. A.- №2004118770/12; Declared 21.06.2004; Published 27.03.2006; Bul. №9

14. Patent 2006113358 RF, MPK A01V 39/16. Machine for processing of the near-trunk area in rows of perennial plantings / Brosalin V.G., Manaenkov K. A.№2006113358/12; Declared 19.04.2006; Published 20.11.2007; Bul. №32

15. Patent 2007127047 RF, MPK A01V 39/00. Machine for processing of the near-trunk areas in the garden / Brosalin V. G., Manaenkov K. A.- №2007127047/12; Declared 16.07.2007; Published 27.01.2009; Bul. №3

16. Patent 2350060 RF, MPK A01V 39/16. Machine for processing of the near-trunk areas in the garden / Brosalin V. G., Manaenkov K. A.- №2007127047/12; Declared 16.07.2007; Published 27.03.2009; Bul. №9

17. Patent 2405292 RF, MPK A01V 39/1 Machine for processing of the near-trunk areas in the garden / Brosalin V. G., Manaenkov K. A.- №2009120825/21; Declared 01.06.2009; Published 10.12.2010; Bul. №34

18. Patent $101324 \mathrm{RF}, \mathrm{MPK}$ A01M 21/00. A flame cultivator for the treatment of weeds in the near-trunks areas in the garden / Pustovalov A.V., Shipovsky A.K., Pustovalov V.S.- №2010132006/15; Declared 29.07.2010; Published 20.01.2011; Bul. №2

19. Patent 2412569 RF, MPK A01V 39/16. Machine for processing of the near-trunk areas in the garden / Brosalin V. G., Manaenkov K. A. - №2009132273/21; Declared 26.08.2009; Published 27.02.2011; Bul. №6

20. Patent 2281636 RF. MPK A01V 39/16. Tillage cutter for processing the near-trunk areas in gardens / Trubilin E.I., Tomchuk R.V.- №2005101525/12; Declared 24.01.2005; Published 20.08.2006; Bul. №23

21. Patent 2005101525 RF, MPK A01V 39/16. Tillage cutter for processing the neartrunk areas in gardens / Trubilin E.I., Tomchuk R.V. - №2005101525/12; Declared 24.01.2005; Published 10.07.2006; Bul. №19

22. Patent 2343659 RF, MPK A01V 35/16, A01V 39/20. Machine for processing of soil in inter-rows fruiting garden / Modovnik A.N., Tverdokhlebov S.A., Tarasenko B.F.№2007130072/12; Declared 06.08.2007; Published 20.01.2009; Bul. №2

23. Patent 2384034 RF, MPK A01V 39/16. Tillage cutter for processing the near-trunk areas in gardens / Trubilin E.I., Trubilin A.I., Sidorenko S.M.- №2008145525/12; Declared 18.11.2008; Published 20.03.2010; Bul. №8. 